\title{
Vivências de prazer e sofrimento no trabalho de profissionais de uma fundação pública de pesquisa
}

Experiences of pleasure and suffering in the work of a professional public research foundation

Experiencias de placer y sufrimiento en el trabajo de los profesionales de una fundación pública de investigación

\author{
Magda Maria Augusto* \\ Lêda Gonçalves de Freitas* \\ Ana Magnólia Mendes ${ }^{* *+}$
}

\begin{abstract}
Resumo
Este estudo investiga as vivências de prazer e sofrimento de trabalhadores de uma fundação pública de pesquisa. Busca-se caracterizar o contexto de trabalho nas dimensões da organização do trabalho, condições e relações socioprofissionais, descrever as vivências de prazer esofrimento, einvestigar os mecanismos utilizados para mediar o sofrimento. A psicodinâmica do trabalho foi a abordagem teórica utilizada para fundamentar a pesquisa. Foram realizadas duas entrevistas semiestruturadas coletivas com dois grupos de trabalhadores. As entrevistas foram analisadas por meio da análise de núcleo de sentido. Os resultados indicam uma forte presença dos princípios do taylorismo, os quais estão associados às vivências de sofrimento. A organização do trabalho causa mais sofrimento do que as relações socioprofissionais. As condiçōes de trabalho se revelaram precárias quanto ao desenho dos postos de trabalho, o que contribui para a destruição das relações nas organizaçóes públicas, podendo trazer consequências indesejáveis à qualidade dos serviços prestados à sociedade. Por fim, ressaltam-se as estratégias defensivas dos funcionários em estágio probatório que, por medo do desemprego, cooperam sem questionamentos com as instâncias superiores, prevalecendo o silêncio em função do medo e da coerção.
\end{abstract}

Palavras-chave: Psicodinâmica do trabalho. Prazer. Sofrimento. Fundação pública.

\footnotetext{
Mestra em Psicologia pela Universidade Católica de Brasília.

** Doutora em Psicologia Social e do Trabalho, mestra em Educação, professora permanente do Mestrado em Psicologia da Universidade Católica de Brasília. E-mail: ledag@ucb.br.

*** Doutorado em Psicologia pela Universidade de Brasília, professora adjunta MS 4 da Universidade de Brasília.
} 


\section{Abstract}

This study investigates the experiences of pleasure and suffering of workers in a public research foundation. We aim at characterizing the work context in the dimensions of work organization, socio-professional relationships and conditions, describing the experiences of pleasure and pain and investigating the mechanisms used to mediate pain. The psychodynamics of work was the theoretical approach used to support research. Two collective semi-structured interviews with two groups of workers were held. The interviews were analyzed by analysis of Nucleus Sense. The results indicate a strong presence of the principles of Taylorism, which are associated with experiences of suffering. The work organization causes more suffering than the social and professional relationships. Working conditions have proved to be precarious for the design of jobs, which contributes to the destruction of public relations in organizations and may bring about undesirable consequences to the quality of services rendered to society. Finally, we emphasize the defensive strategies of employees on probation who, for fear of unemployment, unquestioningly cooperate with the higher authorities, remain silent due to the fear and coercion.

Keywords: Psychodynamics of work. Pleasure. Suffering. Public foundation.

\section{Resumen}

Este estudio investiga las experiencias de placer y sufrimiento de los trabajadores de una fundación pública de investigación. Buscamos caracterizar el contexto de trabajo en las dimensiones de la organización del trabajo, las condiciones y las relaciones socio-profesionales, describir las experiencias de placer y sufrimiento, e investigar los mecanismos utilizados para mediar el sufrimiento. La psicodinámica de trabajo fue el enfoque teórico utilizado para basar la investigación. Se realizaron dos entrevistas semi-estructuradas colectivas con dos grupos de trabajadores. Las entrevistas fueron analizadas con el análisis de núcleo de sentido. Los resultados indican una fuerte presencia de los principios del taylorismo que se asocian con experiencias de sufrimiento. La organización del trabajo provoca más sufrimiento que las relaciones socio-profesionales. Las condiciones de trabajo se revelan precarias para el diseño de los puestos de trabajo, lo que contribuye a la destrucción de las relaciones en las organizaciones públicas y puede traer consecuencias no deseadas a la calidad de los servicios prestados a la sociedad. Por último, se destacan las estrategias defensivas de los empleados en período de prueba que, por miedo al desempleo, cooperan sin cuestionamientos con las 
autoridades superiores, prevaleciendo el silencio, debido al miedo y a la coerción.

Palabras clave: Psicodinámica del trabajo. Placer. Sufrimiento. Fundación pública.

\section{Introdução}

- ste artigo é o resultado de um estudo realizado com trabalhadores de uma fundação pública que é responsável pela pesquisa no Brasil. O estudo teve como referencial teórico a psicodinâmica do trabalho. A problemática central é a influência do contexto de trabalho nas dimensões organização, relações socioprofissionais e condições de trabalho nas vivências de prazer e sofrimento dos sujeitos trabalhadores de uma fundação pública.

A psicodinâmica do trabalho investiga a saúde no trabalho e analisa o sofrimento e as estratégias de mediação utilizadas pelos trabalhadores para ressignificar e superar o sofrimento, com vistas à transformação do contexto de trabalho em um lugar de prazer (Ferreira \& Mendes, 2003). Essa abordagem apresenta-se como relevante referencial teórico no campo da saúde mental, no contexto de trabalho. Dejours (2008, p. 94) assinala que a análise psicodinâmica é um termo proveniente da teoria psicanalítica, que designa o estudo dos movimentos psicoafetivos gerados pela evolução dos conflitos inter e intrassubjetivos.

Dejours (2008, p. 31) constata que o avanço tecnológico e as novas organizações do trabalho não trouxeram o anunciado fim do trabalho penoso, ao contrário, acentuaram as desigualdades e a injustiça social, e trouxeram formas de sofrimento qualitativamente mais complexas e sutis, sobretudo do ponto de vista psíquico. Aproxima, assim, o idealizador da psicodinâmica do trabalho ao pensamento de Hannah Arendt (2005), que julga ver a redução do trabalho, no mundo contemporâneo, a um esforço rotineiro e cansativo com o único objetivo da sobrevivência (Albornoz, 2008, p. 49). Tanto para Arendt (2005) quanto para Dejours (2008), o sofrimento é inerente ao trabalho.

Para a psicodinâmica, o trabalho ocupa um lugar central na construção da identidade, das formas de sociabilidade e da autoestima, bem como na determinação do sofrimento psíquico. A psicodinâmica do trabalho vem em busca da compreensão da dinâmica psíquica diante dos conflitos gerados quando do confronto entre o desejo do sujeito trabalhador e os modelos de gestão do trabalho. 
A opção metodológica deste estudo prioriza entrevistas coletivas com vistas ao estímulo à construção de um espaço público de discussão e a finalidade de proporcionar uma reflexão capaz de conduzir os sujeitos a se reapropriarem da realidade de seu trabalho. De acordo com Dejours (2008, p. 33), é por meio da reflexão que os trabalhadores podem impulsionar a mobilização necessária para as transformações das situações dolosas do trabalho em situações saudáveis.

O objetivo geral deste estudo é investigar as vivências de prazer e sofrimento no trabalho de profissionais de uma fundação pública. Especificamente, busca-se:

a) caracterizar o contexto de trabalho nas dimensões da organização do trabalho, condições e relações socioprofissionais;

b) descrever as vivências de prazer e sofrimento;

c) investigar os mecanismos utilizados pelos trabalhadores para mediar o sofrimento relacionado ao trabalho.

\section{Psicodinâmica do trabalho}

A psicodinâmica do trabalho, de acordo com Dejours (2004), é uma abordagem científica que estuda o sujeito e sua relação com a organização do trabalho, sendo esta determinante do sofrimento mental. Para Dejours (1992), a organização do trabalho produz sobre o homem ações específicas em seu aparelho específico, tendo em vista que, em determinadas contextos de trabalho, surge um sofrimento em decorrência do choque entre os desejos pessoais do sujeito que trabalha e uma organização que não acolhe os sonhos e esperanças desse sujeito trabalhador.

Todo trabalho tem a resistência do real, e a experiência do real é afetiva, pois que trabalhar é sempre fracassar, sofrer (Dejours, 2008). O sujeito trabalhador tem de fazer frente ao real até descobrir ou inventar a solução, ou seja, reconhecer, assumir o sofrimento e resistir ao fracasso, acrescentando ao prescrito para realizar a tarefa (o que Dejours conceitua como "trabalho vivo"). Assim, trabalho vivo está relacionado ao poder do trabalhador em sentir, pensar, inventar, criar e recriar o seu fazer cotidiano nas organizaçóes de trabalho (Dejours, 2008). Para o autor, o sofrimento é assim entendido como o modo fundamental pelo qual se dá o trabalho. Trabalhar é mais que produzir, é transformar a si mesmo.

O contexto de trabalho apresenta-se como o cenário em que se desenvolvem as significações psíquicas e a construção de relações intersubjetivas, designadas 
relações socioprofissionais, possibilitadas pelas condições de trabalho e mediadas pela organização do trabalho. Esse cenário possibilita o fortalecimento da singularidade do sujeito.

O contexto de trabalho, nas suas três dimensões (organização do trabalho, condições de trabalho e relações socioprofissionais), influencia o prazer e o sofrimento, que são constitutivos da subjetividade no trabalho. São vivências que retratam o sentido dado ao trabalho como resultante da interação entre condições subjetivas (dos sujeitos) e objetivas (da realidade de trabalho). Nesse contexto, o trabalhador despende energia, individual e coletivamente, na busca de dar conta da realização da atividade. Assim, ele poderá vivenciar prazer e, ou, sofrimento. Caso predomine o sofrimento, poderá utilizar-se de estratégias de mobilização ou defensivas ou operatórias.

O contexto de trabalho se caracteriza pela organização, condiçôes e relações de trabalho, conforme estudo realizado por Ferreira e Mendes (2003) com auditores fiscais da Previdência Social Brasileira. Segundo os autores, a organização do trabalho é constituída pelos elementos prescritos (formal ou informalmente) que expressam as concepções e as práticas de gestão de pessoas e do trabalho presentes no lócus de produção e balizam o seu funcionamento. Para Dejours (1992), a organização do trabalho diz respeito não somente à divisão do trabalho, mas, principalmente, às divisões dos homens com vista a garantir a divisão das tarefas que são representadas pelas hierarquias, controles e divisões de responsabilidades.

Para Ferreira e Mendes (2003), as condições de trabalho são constituídas pelos elementos estruturais que expressam as condições de trabalho presentes no lócus de produção e caracterizam sua infraestrutura, apoio e práticas administrativas. Essa dimensão é integrada pelos elementos:

a) ambiente físico: sinalização, espaço, ar, luz, temperatura, som;

b) instrumentos: ferramentas, máquinas, documentação;

c) equipamentos: materiais arquitetônicos, aparelhagem, mobiliário;

d) matéria-prima: objetos materiais/simbólicos;

e) suporte organizacional: remuneração, desenvolvimento de pessoal e benefícios.

As relações socioprofissionais são constituídas pelos elementos 
interacionais que expressam as relações interpessoais presentes no cenário de trabalho e caracterizam sua dimensão social. Os elementos que integram essa dimensão são os seguintes:

a) interações hierárquicas: chefias superiores;

b) interaçõos coletivas intra e intergrupos: membros da equipe de trabalho, membros de outros grupos de trabalho;

c) interações externas: usuários, consumidores, representantes institucionais (Ferreira \& Mendes, 2003).

Freitas (2006, p. 104) constata que o trabalho é um processo dialético: de um lado, o sujeito trabalhador, que dá sentido ao que faz; de outro, as situações de trabalho, ou seja, o trabalho real, as quais impactam sobre as percepções desse trabalhador em relação a todo o contexto de trabalho. Diante dessa dialética, o trabalhador pode ter vivências de prazer e, ou, sofrimento. As vivências de sofrimento podem se expressar pelos males causados no corpo, na mente e nas relações socioprofissionais; portanto as suas causas advêm do contexto de trabalho. O sofrimento pode constituir um indicador de saúde, pois, para além de ser uma vivência de afetos dolorosos, é um mobilizador para as mudanças das situações que fazem sofrer, quando é ressignificado pelo uso eficaz de estratégias de mediação oportunizadas por determinado contexto de trabalho. "Se o sofrimento não é acompanhado por uma descompensação psicológica é porque contra ele o sujeito emprega defesas que lhe permite controlálo" (Dejours, 2008, p. 35).

As vivências de prazer, em contrapartida, surgem do amálgama que o trabalho traz para o corpo, a psique e as relações interpessoais. As suas causas originam-se das dimensões que estruturam o contexto de trabalho. As vivências de prazer se manifestam por meio da gratificação, da realização, do reconhecimento, da liberdade e da valorização no trabalho. Constituem como um dos indicadores de saúde no trabalho por possibilitarem a estruturação psíquica, a identidade e a expressão da subjetividade no trabalho, de modo a viabilizar as negociações, a formação de compromisso e a ressonância entre o subjetivo e a realidade concreta de trabalho (Dejours, 2008).

Diante dos desafios do contexto de trabalho, as estratégias de mediação individual e coletiva trazem à tona os modos de pensar, sentir e agir dos trabalhadores frente às contradições presentes no ato de trabalhar. As estratégias buscam garantir o predomínio de vivências de prazer, bem 
como transformar as dificuldades do contexto de trabalho, de maneira a assegurar a integridade física, psicológica e social dos trabalhadores. Visam a tornar possível a superação, a ressignificação e, ou, transformação do sofrimento no trabalho, proporcionando a predominância de vivências de prazer e saúde no trabalho (Freitas, 2006).

Para fazer frente aos constrangimentos oriundos da organização do trabalho, o indivíduo utiliza do recurso da mobilização subjetiva, que o impele a extravasar os recursos de sua inteligência e de sua personalidade. Esse recurso viabiliza a administração coletiva da organização do trabalho, posto que afasta a possibilidade de adoecimento psíquico e minimiza a necessidade do uso de estratégias defensivas, conforme assertiva de Ferreira e Mendes (2003).

A cooperação, colaboração dos trabalhadores à organização do trabalho, assegura a vontade das pessoas de trabalharem juntas e de superarem coletivamente as contradiçóes que surgem da própria natureza ou da essência da organização prescrita do trabalho, atuando decisivamente tanto em relação à eficiência do trabalho quanto em relação à economia do sofrimento.

Assim, a cooperação apresenta-se a partir da mobilização subjetiva, que, por sua vez, depende da dinâmica contribuição/retribuição para seu surgimento. Para Dejours (2008), a cooperação se viabiliza pelo espaço público de discussão que é construído pelos trabalhadores. Nesse espaço, experiências são partilhadas e, efetivamente, a coordenação das atividades se constitui, propiciando o enfrentamento do sofrimento advindo da organização do trabalho.

Dejours (2008, p. 23) entende que a mobilização tem sua principal fonte de energia não na esperança de felicidade, pois sempre duvidamos dos resultados de uma transformação política, mas na cólera contra o sofrimento e a injustiça considerados intoleráveis. Em outras palavras, a ação coletiva seria mais reação do que ação, reação contra o intolerável, mais que ação voltada para a felicidade.

Para a psicodinâmica do trabalho, ao confrontar o real do trabalho, o sujeito experiência inevitavelmente o sofrimento, e a condição necessária para a transformação do sofrimento em prazer é o reconhecimento. Somente o reconhecimento pode dar a real dimensão para os sujeitos de sua utilidade para a organização e também de seu pertencimento a um coletivo de trabalho. 
Dejours (2008) apresenta duas formas de reconhecimento: o reconhecimento baseado em um julgamento de utilidade e o baseado no julgamento da beleza. Enquanto o primeiro é atestado pelos superiores hierárquicos, o segundo emerge dos pares.

Dessa forma, o destino do sofrimento no trabalho está intrinsecamente ligado ao reconhecimento. Quando o sujeito tem autenticada a utilidade ou a beleza de seu ofício, todo o sofrimento vivido no encontro com o real do trabalho pode ser ressignificado e transformado em prazer.

\section{Método}

\subsection{Participantes}

Participaram do estudo 14 funcionários de uma fundação pública, sendo 4 do sexo masculino e 10 do sexo feminino, com faixa etária entre 29 e 52 anos. $\mathrm{Na}$ organização, o tempo de serviço dos participantes variou de 21 meses a 28 anos. Todos os participantes têm nível superior completo, sendo 3 com doutorado, 6 com mestrado, 3 com especialização e 2 com graduação.

\subsection{Entrevista semiestruturada coletiva}

A entrevista semiestruturada/coletiva foi conduzida de acordo com o roteiro apresentado por Mendes (2007), em quatro eixos temáticos:

1) organização do trabalho, compreendendo o prescrito, as condições para execução e as relações socioprofissionais envolvidas;

2) prazer e sofrimento provenientes do trabalho;

3) as formas de enfrentamento do sofrimento no trabalho;

4) os possíveis impactos sobre a saúde.

\subsection{Procedimentos para a coleta de dados}

Foram realizadas duas entrevistas. Cada entrevista, que foi gravada e transcrita integralmente, durou cerca de duas horas e foi conduzida pela pesquisadora.

\subsection{Análise dos dados}

Os resultados foram avaliados com base na técnica de Análise do Núcleo de Sentido (ANS), apresentada por Mendes (2007), que se referenciou na 
análise de conteúdo categorial de Bardin (1988), priorizando os aspectos reais e simbólicos da interação do sujeito com o seu contexto de trabalho.

\section{Resultados}

Aqui são destacados os resultados do estudo, os quais foram organizados com base nos núcleos de sentidos. Os três primeiros núcleos são referentes ao contexto de trabalho nas dimensões organização do trabalho, relações socioprofissionais e contexto de trabalho, respectivamente. O quarto núcleo indica os sentimentos de prazer no trabalho. O quinto se refere ao sofrimento no trabalho. Por fim, salienta-se que o núcleo sintetiza o enfrentamento do sofrimento no trabalho. A descrição dos núcleos é exemplificada com as verbalizações dos participantes da pesquisa.

\subsection{Descrição dos núcleos de sentidos}

Núcleo 1: "É sempre aquele trabalho rotineiro, sempre as mesmas coisas"

Os sujeitos pesquisados afirmam que o trabalho na organização é repetitivo, burocrático, limitado e chato. Os trabalhadores avaliam que são muitas pessoas nos lugares errados, faltando análise de cargos, gestão por competência. O recrutamento e a seleção de pessoal são descritas como ineficientes. Os sujeitos indicam que reproduzem os procedimentos sem reflexão e, quando alguém questiona, é tido como subversivo. Eles trabalham em torno de 8 a 10 horas por dia, sentados em frente ao computador. Destacam que permanecem na mesma posição com a mão no mouse durante toda a jornada de trabalho. Há uma sobrecarga de trabalho na organização analisada. Os sujeitos pesquisados indicam que há problemas de saúde por esforço repetitivo. A organização segue modelos padronizados de organização do trabalho do setor privado, que não têm a mesma lógica do setor público: "É sempre aquele trabalho rotineiro, sempre as mesmas coisas". "O meu trabalho também é um pouco repetitivo [...]." "Meu trabalho atualmente está chato. Eu acho que serviço público, serviço burocrático é muito chato".

Os trabalhadores informam que são cobrados dentro de prazos apertados por conta da agregação de procedimentos desnecessários que dificultam a realização do trabalho. Não há diálogo ou discussão, eles têm de executar as tarefas do jeito que o chefe quer, reproduzindo procedimentos sem parar para refletir se aquele procedimento ainda é viável, adequado ao 
momento. Quando é preciso mudar algum regulamento ou norma, os técnicos que operacionalizam os programas não são ouvidos, não participam. $\mathrm{O}$ trabalho na organização não apresenta desafios, segue-se à risca o trabalho prescrito e, se alguém questiona, é tido como subversivo. Os funcionários alegam que não há espaço para a criatividade. As decisões são tomadas sem qualquer participação dos trabalhadores, são decisões tomadas somente pela hierarquia institucional.

Você é cobrado por prazos que, às vezes, ficam prazos apertados por conta de agregação de procedimentos desnecessários [...].

Em termos de participação da gente, inexiste. Os regulamentos e as portarias, no entanto, muito próprio da minha área. Quando vai ter alguma alteração nas portarias, nós que somos técnicos que trabalhamos na operacionalização do programa não somos ouvidos, ou seja, a gente que participa e vê a necessidade da mudança, quando tem que mudar alguma coisa, algumas normas não acontecem, e vem sempre de cima para baixo.

Núcleo 2: "Vou contar uma coisa para vocês, eu cheguei em uma mesa de colegas, e uma pessoa mais antiga disse que eu era de confiança e que os colegas podiam falar, então há um grupo de um lado e um grupo do outro"

Os profissionais afirmam que o contexto institucional é péssimo, que os gestores da organização cortam a fala dos funcionários. Eles afirmam que não há espaço para se colocarem. Os gestores aproveitam do poder dos cargos de confiança para exercerem o controle sobre os trabalhadores. Estes constatam que a gestão dos recursos humanos da organização é extremamente arcaica, pois a forma de perceber as pessoas tem resquícios do militarismo e, quando algum trabalhador chama para reflexão, é olhado de lado, ficando excluído como se fosse aquele que quer bagunçar a ordem que já está posta.

Hoje eu me encontro trabalhando neste prédio lindo, que, quando eu venho, olho e falo: nossa, é o prédio mais bonito do Setor Bancário Norte. Eu fico pensando "pra que tudo isso, se o clima organizacional é péssimo aqui dentro?”.

Os trabalhadores sentem-se destratados pela organização, pois são comparados a objetos, coisas. Compreendem que não há possibilidade de apresentar sugestões aos "superiores", visto que tal participação não é bem-vinda. Quanto às relações entre os pares, os funcionários destacaram 
que há dois grupos na organização, denominados de confiáveis e não confiáveis. Os confiáveis estão entre os novatos e os antigos, outra divisão da organização. Em que pese uma organização com vários grupos, trabalhadores indicam que há solidariedade entre os pares.

A impressão que a organização tem demonstrado é que não há interesse dela na pessoa, no ser humano. Para ela (organização), tanto faz ter só a mesa: eu não sei quem produz. Somos nós que sustentamos a organização, somos nós que produzimos. Então o tratamento que tem sido dado ao servidor, de um modo geral, é tão "destratável".

[...] esse problema de as pessoas não conseguirem dar vazão para a criatividade. Sugestões novas nunca são bem-vindas, qualquer sugestão que fuja daquele padrão já preestabelecido há algumas décadas.

Núcleo 3: "A arquitetura para mim propicia isso, trabalhar com 50 pessoas, ouvir 50 pessoas lá onde eu trabalho é assim, vê e ouve as pessoas o tempo todo [...]"

Os servidores relatam que a mudança de prédio ocorrida foi um duro golpe propiciado pela arquitetura. As salas não oferecem nenhuma privacidade e dificultam a concentração, tendo em vista que não existem divisórias nos andares. Ficam todos no mesmo amplo salão, onde se ouve e se vê todo mundo. A distribuição do espaço em "ilhas de trabalho" propicia desconforto aos trabalhadores, o qual advém da falta de privacidade e do barulho que dificulta a concentração. "A mudança do prédio foi um duro golpe para mim, e eu achei que teria que ir ao psiquiatra para tomar antidepressivo, mas dei a volta por cima, mudei de lugar na sala."

A área de informática é vista como o calcanhar de aquiles da organização, não oferecendo o suporte necessário para a realização do trabalho. As instituições de ensino superior demandam muito tempo do técnico para explicaçôes sobre os sistemas informacionais da organização, pois estes são de difícil execução.

A organização é tão isso e tão aquilo, mas o sistema de informática é uma porcaria. Então ficamos com essa pendência, mas quem senta para fazer essas reuniōes são os que têm funções comissionadas; assumido para chefiar, chegam nas reuniōes e dizem que está tudo bem.

Os funcionários revelam que o salário é compatível com as atividades desenvolvidas e a estabilidade no emprego é um aspecto motivador. Eles 
evidenciam que, fisicamente, por conta da função, e com o passar do tempo, vão aparecendo algumas lesões, algumas patologias, porque, embora haja o serviço de qualidade de vida, algumas questôes mais específicas vão passando despercebidas.

Núcleo 4: "A satisfação de responder ao público e receber o elogio, muito bom a pessoa te dar um retorno, você responde um e-mail, e a pessoa agradece a você, por telefone [...]"

Os funcionários relatam que têm uma boa relação com os colegas e com o público externo. Eles demonstram satisfação de atender o público externo, visto que há elogios, e sentem-se felizes pelo bom retorno do público que atendem. "Eu, graças a Deus, me relaciono bem com meus colegas. Tenho para mim que eles também me toleram. Isso é muito bom e também a satisfação de receber um elogio."

Os funcionários informam que o salário na empresa corresponde às tarefas desempenhadas; relatam que os servidores antigos têm uma relação afetiva com a organização, o que facilita o trabalhar. Outro motivo de satisfação com o trabalho diz respeito ao apoio para os estudos. Segundo os pesquisados, a organização oferece incentivos para os trabalhadores estudarem nos diversos níveis: aperfeiçoamento, especialização, mestrado e doutorado. Outro fator que gera a satisfação é a estabilidade do emprego público.

Um elogio para a organização, pois nem tudo é tão ruim assim. Eu acho importante esse apoio que a organização dá para a gente estudar. Eu gosto desse ambiente, ela está sempre incentivando, oferecendo coisas alternativas; isso eu acho dez.

Núcleo 5: "Em relação a sentimento, é um dos motivos que estou mudando, porque eu não me sinto satisfeito, me sinto frustrado"

As pessoas optam por subirem de escadas até suas salas para evitar o encontro com pessoas que as aborreceriam; relatam que os servidores da organização estão assombrados, com medo (dos desmandos de algumas chefias) e pensando, inclusive, em pedir demissão. Os funcionários afirmam que há frustração e tristeza por conta do ambiente de trabalho, que não se sentem bem na organização e se queixam que ninguém está a fim de ouvilos. Eles dizem estar cansados de oferecerem sugestōes ao trabalho que são comumente descartadas e ressentem-se da total falta de autonomia, já que sequer permitem que nomeiem um documento. Os funcionários sentem-se 
podados, "robozinhos"; eles têm de executar e não pensar, é assim que os chefes agem, segundo os resultados das entrevistas.

Acho que o sentimento de frustração é compartilhado por muitos colegas que passaram neste último concurso para esta organização. Ninguém esperava encontrar o ambiente de trabalho que encontrou aqui [...]

Ninguém está a fim de te ouvir. Como é que você pode gostar de um lugar desses, como é você pode suportar um negócio desses? Eu acho intolerável. Claro que a pessoa tem de ficar doente, enfartar, eu não vou entrar em depressão porque eu conheço pessoas em situações bem piores que a minha [...].

Outro ponto relevante ao sofrimento diz respeito ao fato de a gestão ser personalizada, em que as demandas são atendidas de acordo com o cliente que está por trás daquela necessidade. Os funcionários declaram que os servidores estão adoecendo, fato que vem preocupando inclusive médicos que participam da perícia médica governamental, que encaram esse fato como questão de saúde pública, tal a frequência de servidores abaixo de 39 anos que estão tomando medicamentos de tarja preta. Os funcionários destacam que as pessoas adoecem porque a gestão é doente.

Dependendo do cliente aquela demanda recebe um tratamento preferencial ou não, o benefício é concedido ou não. E isso me deixa muito chateado, e, no mais, o que me chateia é ver que todas as pessoas [...] elas estão todas assombradas, com medo, ao ponto de pessoas não terem outra alternativa, mesmo sem alternativa, pensam até em pedir demissão.

Para os participantes da pesquisa, o modelo de gestão organizacional gera insegurança constante nos funcionários, já que há um processo de tensão permanente no contexto de trabalho. A insatisfação com a organização é uma constante nas falas dos entrevistados, além do estresse da natureza do trabalho, qual seja, trabalhar o dia inteiro com computador.

Eu acho que esse modelo instalou, dentro da organização, um estado de insegurança porque eu trabalho na organização tem uns 12 anos, e eu não percebia isso antes, no início. Depois de certo tempo que retornei, eu percebi isso. Ficamos em estado de tensão permanente.

É como eu me sinto, em vir pensando para cá que é mais um dia, e de não querer vir para este lugar nunca mais, cansei. 
Núcleo 6: "O recurso que eu utilizo é o seguinte: eu tenho uma coisa que me move que é a esperança, e é com essa ideia fixa, com a esperança de que isso vai melhorar, é que venho todo dia para trabalhar na organização"

Os trabalhadores utilizam-se do boicote para fazer resistência às atitudes arbitrárias da gestão. Relatam que ainda não adoeceram porque se apegam ao sentimento de esperança de que as coisas vão melhorar. Além disso, informam ter esperança na capacidade de organização da associação dos funcionários para que as coisas venham a melhorar na empresa. Eles sentem que podem fazer diferente se continuarem sempre lutando como servidores públicos, ao cumprir com as suas responsabilidades. Uma estratégia bastante usada é a noção de responsabilidade, de trabalhar para cumprir com seu dever de servidor público.

Essa questão do boicote, eu vejo como resistência, e essa resistência é uma forma de poder. Quando tem a relação de dominador e dominado, que são essas atitudes arbitrárias, mas se esquecem que, mesmo silenciosamente, as pessoas vão se manifestando, o boicote é uma resistência. Estamos exercendo, mesmo que timidamente, o nosso poder contra essas ações arbitrárias.

O salário constitui, também, um fator contra o sofrimento. Dizem pensar "mil vezes" antes de abrir mão (pedir demissão) desse "serviço chato" por causa da estabilidade. Os funcionários evitam os elevadores, fazendo uso de escadas, não por "medo" de encontrarem determinados gestores, mas para não se aborrecerem. Alguns acham melhor pedir demissão por não terem alternativas. Eles percebem que a "empresa” está doente, não as pessoas. Os funcionários afirmam não acreditarem mais em coletivo, buscando estratégias individuais contra o adoecimento. Para tanto, alguns alternam de setor como estratégia contra o desestímulo. Outros buscam o prazer fora do trabalho; buscam equilíbrio em outras tarefas colocando a criatividade para fora: estudam, desenham, lecionam, escrevem artigos, livros e montam bandas, como válvula de escape. Eles enfatizaram as relações entre os pares como motivadoras para o exercício da função.

O salário que tenho para receber no final do mês me move. Pagar as contas; estou no ritmo da nossa colega, aguardando a minha aposentadoria, e é isso que tem me movido. Por esta estabilidade você precisa pensar mil vezes antes de abrir mão desse serviço chato. 


\section{Discussão}

No contexto de trabalho investigado, os trabalhadores não participam das decisões. Segundo Lancman (2008, p. 176), em situações em que não há margem de manobra, em que o trabalhador não pode contribuir com sua experiência e seu saber fazer ou não consegue realizar seu trabalho de acordo com seus princípios e crenças, ele está impedido de transformar seu sofrimento em ações significativas que o levem ao prazer. Nesse caso, o trabalho pode se constituir em fator considerável de geração de sofrimento patogênico, de desequilíbrio, de doenças.

A organização do trabalho apresenta-se extremamente hierarquizada, rígida e burocrática. Para Mendes e Siqueira (2009, p. 243),

Rever estruturas, torná-las maisleves, flexíveis ehorizontalizadas são ações fundamentais para estabelecer uma máquina pública que cumpra efetivamente suas funçôes. A reforma gerencial, a dita mudança do paradigma burocrático para o pós-burocrático ou gerencial, faz-se necessária.

Quando os trabalhadores são impedidos de questionar, sob pena de serem tidos como subversivos, separa-se o trabalho manual do intelectual, lógica do modelo taylorista de organização do trabalho, e a atividade mental dos trabalhadores é neutralizada. O trabalho passa a ser repetitivo, monótono, sem qualquer possibilidade de realização.

Ainda, no âmbito da organização do trabalho, há uma sobrecarga de trabalho na organização. As pessoas trabalham além das oito horas diárias sem receber hora extra ou qualquer outro incentivo. Mendes e Siqueira (2009, p. 242) buscam estabelecer uma análise crítica do discurso contemporâneo em gestão de pessoas, verificando como o discurso e as práticas gerencialistas se reproduzem no setor público sem que haja a devida análise do fator ideológico que permeia a gestão privada.

Perde-se, assim, a própria significação de seu trabalho em relação ao conjunto da atividade da organização. "Mas, mais do que isso, essa tarefa não tem significação humana. Ela não significa nada para a família, nem para os amigos, nem para o grupo social e nem para o quadro de um ideal social, altruísta, humanista ou político" (Dejours, 1992, p. 49).

Ora, a organização real do trabalho não é tão somente a organização prescrita. Conforme esclarece Dejours (2008, p. 63), a elaboração do trabalho real implica o afastamento das prescriçôes para dar início à atividade de "interpretação", criadora de atividades, de saber fazer e modos operatórios 
novos, possibilitando, assim, o necessário ajuste entre a organização do trabalho prescrito e a organização do trabalho real. De acordo com Dejours (1992, p. 52), da análise do conteúdo significativo do trabalho é preciso reter a antinomia entre satisfação e organização do trabalho. Via de regra, quanto mais a organização do trabalho é rígida, mais a divisão do trabalho é acentuada, menor é o conteúdo significativo do trabalho e menores são as possibilidades de mudá-lo. Correlativamente, o sofrimento aumenta.

Para enfrentar o medo do desemprego que emerge de uma política de coerção (possível reprovação no estágio probatório), os novos servidores elaboram procedimentos defensivos, chegando a cooperar com os atores do comando, ou seja, são investidos de cargos de confiança intermediários, devendo acatar tudo o que vem das instâncias superiores, sem questionamentos. Para Dejours (2008, p. 32), consentir em cooperar supóe, pelo menos em parte, reprimir sua inteligência e sua própria subjetividade.

Segundo Dejours (2008, p. 27), "A perda do poder de barganha de quem procura emprego e a precarização econômica levam os trabalhadores à escolha entre um mau trabalho ou trabalho nenhum"; ainda, entre a instabilidade de um emprego privado e a estabilidade de um emprego público, os servidores acabam por ceder à precarização das condiçôes de trabalho, bem como dos mecanismos de proteção à saúde, colocando-se frente ao sofrimento e ao adoecimento.

No que tange às relações socioprofissionais, o clima organizacional na organização está caótico. Os profissionais não têm espaço de fala. Não há diálogo ou discussão, eles têm de executar as tarefas do jeito que o chefe quer. "A inexistência de um espaço de fala e trocas adequado nas organizações leva à degradação do coleguismo entre os trabalhadores, com a exacerbação dos conflitos e o distanciamento ainda maior entre técnicos e supervisores" (Dejours, 2008, p. 41). Surge, assim, um abismo nos vínculos de confiança e cooperação entre os pares, inviabilizando a construção coletiva de resolução das dificuldades e preservação da saúde.

Ainda sobre os supervisores ou gerentes intermediários, cabe ressaltar que, pelo relato dos servidores, eles não querem se indispor com a hierarquia nem com os trabalhadores. Esses gerentes acreditam agir como engrenagens de um sistema que os transcende. Assim, os trabalhadores lançam mão de uma defesa perversa, negando o sofrimento alheio e calando o seu próprio sofrimento. Em consonância com os resultados deste estudo, afirmam Mendes e Siqueira (2009, p. 244):

A orientação gerencialista está cada vez mais voltada para tarefa 
e menos para pessoas, precarizando o trabalho, desmotivando o servidor e fazendo com que as tarefas laborais pressionem cada vez mais o indivíduo, dificultando a criação de espaços de diálogo e de exercício da criatividade.

O poder, nesse sistema hierarquizado, submete os trabalhadores a uma forma de dominação pela manipulação gerencial da ameaça de precarização. A precarização do trabalho parece caminhar a passos largos, impedindo a construção de um ambiente de trabalho onde se possa construir um espaço, uma cultura, um estado de bem-estar indispensável para a saúde e a realização profissional dos trabalhadores. Os sujeitos pesquisados vivem constantemente com medo. Esse medo é permanente e gera condutas de obediência e até submissão, principalmente naqueles que ainda cumprem o estágio probatório, impedindo, assim, a mobilização subjetiva contra o sofrimento e a alienação. Como disse Sofsky, citado em Dejours (2007, p. 51), a partir de certo nível de sofrimento, "a miséria não une: destrói a reciprocidade”. Em que pesem as condiçōes de trabalho, faltam investimentos institucionais na ergonomia e na qualidade de vida. $O$ excesso de barulho causado pela distribuição do espaço em "ilhas de trabalho" tem propiciado grande desconforto aos trabalhadores. Não há o devido suporte da área de informática (onde se evidencia a maior precariedade das condições de trabalho) para a condução adequada dos trabalhos. Entretanto, mesmo as más condições de trabalho são, no conjunto, menos temíveis do que uma organização de trabalho rígida e imutável (Dejours, 1992, p. 52).

No que diz respeito às vivências de prazer e sofrimento no trabalho, fica evidente a situação crítica em todos os fatores a elas pertinentes. As poucas vivências de prazer no trabalho foram relatadas com base no reconhecimento do público externo, reconhecimento da contribuição do sujeito à sociedade. A esse respeito advoga Dejours (2007, p. 97): "Quando a dinâmica do reconhecimento funciona, o sujeito se beneficia de uma retribuição simbólica que pode inscrever-se no âmbito da realização do ego, no campo social". Outra fonte de prazer diz respeito à política de capacitação de pessoal da organização que incentiva os estudos em todos os níveis, lato e stricto sensu.

Para Dejours, o grande palco do sofrimento, hoje, é o trabalho, tanto para os que dele se acham excluídos quanto para os que nele permanecem. $\mathrm{Na}$ busca por um equilíbrio possível, mesmo à custa de um sofrimento, os trabalhadores se conformam à sombra de critérios sociais de normalidade. Para a psicodinâmica do trabalho, faz-se relevante compreender como 
os trabalhadores conseguem manter certo equilíbrio psíquico, mesmo estando submetidos a condiçôes de trabalho desestruturantes (Dejours, 2008).

Quando relatam que se submetem, na organização, a um trabalho chato, repetitivo e burocrático, e que se adaptam ao trabalho chato, sem, porém, saber quanto sofrimento carregam nessa adaptação, há fortes indicadores de depressão no grupo estudado. Os trabalhadores não percebem sua participação a uma obra útil, ao progresso social, sentem-se desqualificados, mal utilizados. Assim:

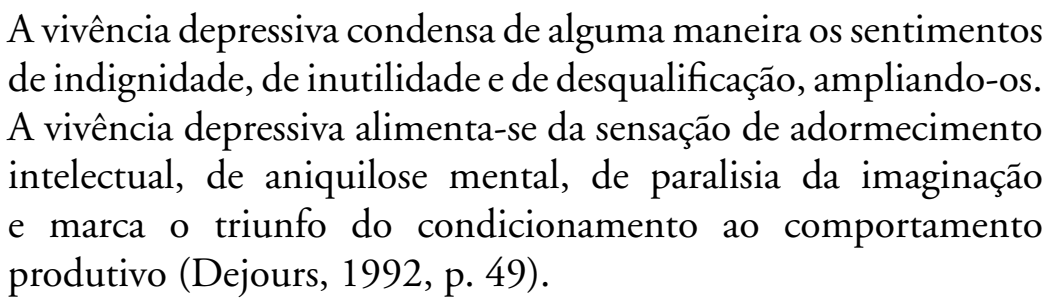

A ocorrência de assédio moral por algumas chefias aparece fortemente no relato dos trabalhadores. Para Dejours (2007, p. 15), o assédio no trabalho nada tem de novo. É antigo como o trabalho. Assim, faz-se necessário reconhecer e analisar a fragilização das pessoas no que se refere ao assédio, fragilização associada à desestruturação dos mecanismos de defesa, em especial as defesas coletivas e a solidariedade.

Há que se tomar sérias e urgentes providências contra o assédio moral. A área de gestão de pessoas precisa assumir seu papel no monitoramento dessa ação, de forma a garantir a construção de ambientes que propiciem a estabilidade do aparelho psíquico dos trabalhadores, bem como a saúde da organização e a consequente oferta de um serviço de qualidade à sociedade. A ação perversa de determinados gestores precisa ser neutralizada por meio de discussões, treinamentos e, quiçá, pela substituição de alguns gestores por indivíduos mais preparados e com personalidades mais adequadas aos cargos de gerência.

Gaulejac, como citado em Mendes e Siqueira (2009), caracteriza a gestão como doente, o que foi parafraseado na fala de um dos sujeitos da pesquisa: "Este é um órgão de doença", ou seja, a organização invade o mundo e pressiona o indivíduo. Em vez de melhorar as relações humanas, desmotiva o indivíduo ao tempo em que contribui para a deterioração e aniquilamento do coletivo de trabalho.

O não reconhecimento, a negação de um espaço para a fala e a falta de autonomia têm acarretado uma carga de sofrimento aos trabalhadores. Segundo 
Martins (2010, p. 109), é a qualidade da dinâmica do reconhecimento, estabelecida no contexto das relaçôes de trabalho, que deverá dar a direção do sofrimento, da mobilização subjetiva e do grau de comprometimento no trabalho.

A organização não leva em conta a formação do funcionário no momento de alocá-lo em determinada área, o que leva à inadequação entre as habilidades da pessoa e as atividades do setor, gerando insatisfação e sofrimento. Os trabalhadores vivenciam um estado de tensão permanente, de insatisfação, frustração e angústia.

No que diz respeito às estratégias de mediação do sofrimento, os servidores buscam equilíbrio com atividades fora do trabalho. Para não refleti-lo no trabalho, na realização profissional, perseguem válvulas de escape que ajudam a permanecerem e irem todos os dias trabalhar. Segundo Dejours (2008, p. 144), o sofrimento não é revelado diretamente, só pode ser captado por meio das defesas. Os trabalhadores lançam mão de estratégias defensivas individuais e coletivas contra o sofrimento para propiciar a manutenção do aparelho psíquico.

Psicologicamente, é mais difícil suportar os constrangimentos das situações de trabalho quando se encontra só, sem a solidariedade dos pares. Para Dejours (2008, p. 145) "trabalhar não é tão só produzir: trabalhar é ainda viver junto". Posto isso, percebe-se, nos resultados da pesquisa, uma tendência ao individualismo, à busca de estratégias individuais de defesa na luta contra o poder dos interesses privados, acarretando as patologias da solidão.

Apesar das estratégias individuais de defesa cumprirem um destacado papel na adaptação ao sofrimento, exercem pouca influência na violência social (assédio moral), posto que são de natureza individual (Dejours, 2007, p. 105).

Segundo a análise da psicodinâmica do trabalho, não são as estruturas psíquicas individuais que são mais frágeis que as de outrora: é a erosão das estratégias coletivas de defesa que constitui uma perda considerável de recursos para a saúde (Dejours, 2008, p. 17). A mobilização coletiva é, então, neutralizada pelo medo e o sofrimento. Segundo Dejours (2008, p. 125), esse medo possibilita a banalidade do mal que se apresenta em três estágios (Dejours, 2007, p. 125): o primeiro estágio é constituído pelos líderes da doutrina neoliberal e da organização concreta do trabalho do mal no teatro das operações. O perfil psicológico mais típico é representado por uma organização da personalidade do tipo perverso ou paranoico. O segundo estágio é constituído pelos colaboradores diretos, que atuam no próprio 
campo das operações ou em suas proximidades. Sua participação ativa se obtém mediante estratégias coletivas e ideologias de defesa. $\mathrm{O}$ terceiro estágio é constituído pela massa dos que recorrem a estratégias de defesa individuais contra o medo.

A estratégia de mediação do sofrimento mais fortemente utilizada pelos sujeitos desta pesquisa aponta para "válvulas de escape", ou seja, os trabalhadores buscam sua realização pessoal fora da organização. Satisfazemse fora do horário de trabalho com atividades que lhes dão prazer (Dejours, 2008).

Como forma de evitar o contato com o sofrimento, os trabalhadores usam as ideologias defensivas, como deixar de tomar iniciativas e cumprir estritamente com o prescrito: "do jeito que o chefe quer"; se fechar, recorrendo ao individualismo: "não acredito mais em coletivo", etc. Assim, o relacionamento é rompido para evitar conflitos (Dejours, 2008).

Mas quando já foram usados todos os mecanismos possíveis e as pressões continuam, o sofrimento se torna patogênico, pois leva ao desequilíbrio psíquico e à descompensação e, consequentemente, à doença.

\section{Considerações finais}

Se trabalhar é sofrer, de acordo com as concepções de Dejours, Freud, Marx e Arendt, trabalhar no serviço público é sofrer duplamente. No contexto social brasileiro, a precarização do trabalho induz a busca frenética por um posto público de trabalho, que acena com a gloriosa "estabilidade no trabalho", ao tempo em que (segundo o modelo neoliberal e seus novos paradigmas de gestão) somente os indivíduos competitivos e, portanto, individualistas podem sobreviver no mercado.

Infelizmente, essa lógica neoliberal encontra, cada vez mais, espaço dentro das instituições públicas, de forma a garantir sujeitos esvaziados de subjetividade e desejos; sujeitos alienados, com seus corpos dóceis a compor os "recursos humanos" das organizações, utilizando, muitas vezes, de ideologias defensivas, quando deixam de tomar iniciativas e assumir responsabilidades.

O fato de o trabalho ser guiado por princípios taylorista e gerencialista contribui para que o espaço público da palavra seja interditado, restringindo, assim, as possibilidades de compartilhamento da inteligência prática e, consequentemente, da cooperação e do reconhecimento. A resistência ao real que se impõe diante da idealização do prescrito produz um sujeito 
apartado de si, que se sente impotente diante desses constrangimentos, não tendo recursos psicológicos e sociais para ressignificar o sofrimento. Por isso podemos concluir que é um grupo em risco, com tendência a desenvolver condutas patológicas prejudiciais às relações sociais, ao desempenho institucional, e, sobretudo, à saúde mental.

As instituições, especialmente as públicas, precisam repensar a organização do trabalho, o exercício do poder, a ética e, principalmente, a forma de lidar com os sofrimentos e suas consequências para o sujeito e a coletividade. Fazse urgente a viabilização de espaços de escuta e intervenção nas organizações, de forma que se possa constituir coletivos de trabalho.

\section{Referências}

Albornoz, S. (2008). O que é trabalho. São Paulo: Brasiliense.

Arendt, H. (2005). A condição humana. Rio de Janeiro: Forense Universitária. Bardin, L. (1988). Análise de conteúdo. Lisboa: Edições 70.

Dejours, C. (1992). A loucura do trabalho: estudo de psicopatologia do trabalho. São Paulo: Cortez-Oboré.

Dejours, C. (2004). Subjetividade, trabalho e ação. Revista Produção, 14 (3), 27-34.

Dejours, C. (2007). A psicodinâmica do trabalho na pós-modernidade. In A. M. Mendes, S. C. Cruz, E. P. Facas (Org.). Diálogos em psicodinâmica do trabalho. Brasília: Paralelo 15.

Dejours, C. (2008). Addendum: da psicopatologia à psicodinâmica do trabalho. In: Lancman, S., Sznelwar, L. I. (Orgs.). Christophe Dejours: da psicopatologia à Psicodinâmica do Trabalho. Brasília: Paralelo 15.

Ferreira, M. C., \& Mendes, A. M. (2003). Trabalho e riscos de adoecimento: $o$ caso dos auditores-fiscais da previdência social brasileira. Brasília: Ler, Pensar e Agir.

Freitas, L. G. (2006). Saúde e processo de adoecimento no trabalho dos professores em ambiente virtual. Brasília: Instituto de Psicologia Social e do Trabalho da Universidade de Brasília (Mimeografado). 
Lancman, S. (Org.). (2008). Politicas públicas e processos de trabalho em saúde mental. Brasília: Paralelo 15.

Martins, S. R. (2010). Considerações clínicas sobre os efeitos da perversão nas novas formas de gestão. In A. M. Mendes (Org.). Violência no trabalho: perspectivas da psicodinâmica, da ergonomia e da sociologia clínica. (pp. 109121). São Paulo: Universidade Presbiteriana Mackenzie.

Mendes, A. M. (2007). Pesquisa em psicodinâmica do trabalho: a clínica do trabalho. In A. M. Mendes (Org.). Psicodinâmica do trabalho: teoria, método e pesquisas. (pp. 65-87). São Paulo: Casa do Psicólogo.

Mendes, A. M., \& Siqueira, M. V. S. (2009, Julho, Setembro). Gestão de pessoas no setor público e a reprodução do discurso do setor privado. Revista do Serviço Público, 60 (3), 241-249. 